NBER WORKING PAPER SERIES

\title{
MEDIA BIAS AND INFLUENCE: EVIDENCE FROM NEWSPAPER ENDORSEMENTS
}

\author{
Brian G. Knight \\ Chun-Fang Chiang \\ Working Paper 14445 \\ http://www.nber.org/papers/w14445
NATIONAL BUREAU OF ECONOMIC RESEARCH
1050 Massachusetts Avenue
Cambridge, MA 02138
October 2008

We thank Pedro Dal Bo, Andrew Foster, Glenn Loury, Jesse Shapiro, Ethan Kaplan, and Fernanda Leite Lopez de Leon for helpful comments. We also thank participants the 2008 PIER Political Economy Conference and participants at numerous university seminars. We also thank Chisoo Kim for providing data on newspaper ownership and historical endorsements. The views expressed herein are those of the author(s) and do not necessarily reflect the views of the National Bureau of Economic Research.

NBER working papers are circulated for discussion and comment purposes. They have not been peerreviewed or been subject to the review by the NBER Board of Directors that accompanies official NBER publications.

(C) 2008 by Brian G. Knight and Chun-Fang Chiang. All rights reserved. Short sections of text, not to exceed two paragraphs, may be quoted without explicit permission provided that full credit, including (C) notice, is given to the source. 
Media Bias and Influence: Evidence from Newspaper Endorsements

Brian G. Knight and Chun-Fang Chiang

NBER Working Paper No. 14445

October 2008

JEL No. D7,H0

\begin{abstract}
$\underline{\text { ABSTRACT }}$
This paper investigates the relationship between media bias and the influence of the media on voting in the context of newspaper endorsements. We first develop a simple econometric model in which voters choose candidates under uncertainty and rely on endorsements from better informed sources. Newspapers are potentially biased in favor of one of the candidates and voters thus rationally account for the credibility of any endorsements. Our primary empirical finding is that endorsements are influential in the sense that voters are more likely to support the recommended candidate after publication of the endorsement. The degree of this influence, however, depends upon the credibility of the endorsement. In this way, endorsements for the Democratic candidate from left-leaning newspapers are less influential than are endorsements from neutral or right-leaning newspapers, and likewise for endorsements for the Republican. These findings suggest that voters do rely on the media for information during campaigns but that the extent of this reliance depends upon the degree and direction of any bias.
\end{abstract}

Brian G. Knight

Brown University

Department of Economics, Box B

64 Waterman Street

Providence, RI 02912

and NBER

Brian_Knight@brown.edu

Chun-Fang Chiang

Brown University

Box B

Providence, RI 02912

chunfang.tw@gmail.com 


\section{Introduction}

Voters are often uncertain as to which candidate to support when going to the polling booth and may thus attempt to gather information regarding candidates from better informed sources. One important potential source for such information is the media, which has traditionally been viewed a key ingredient in the development of a well-functioning democracy. While this potential role for the media in providing information to voters is widely recognized, there is also significant concern among voters and political commentators alike that such information may not be sufficiently objective. According to recent survey data, over one-half of voters perceive that the media is politically biased in its reporting, and these perceptions of media bias have increased over time (Pew, 2005). If voters are unsophisticated and do not adequately account for any political bias in information provided by the media, then left-leaning media sources may systematically improve electoral outcomes for Democratic candidates and likewise for right-leaning media sources and Republican candidates. In this case, media bias may lead to poor decisions by voters in terms of selecting relatively low-quality candidates for office.

A key question regarding the role of media in democracies is then whether voters are sufficiently sophisticated to filter out any media bias and, correspondingly, to reduce their reliance on biased reporting when choosing between political candidates in elections. Survey questions regarding trust in the media suggest that voters do attempt to filter out media bias. In particular, according to recent survey data, over 40 percent of respondents report that they have "hardly any confidence in the media", as opposed to "a great deal of confidence" or "some confidence" in the media. Moreover, the fraction of voters lacking confidence in the media has more than doubled over the past three decades, mirroring the recent upward trend in voter perceptions of media bias (Pew, 2005).

These relatively low levels of media credibility are certainly suggestive that voters do attempt to filter out media bias. Yet there is little direct evidence that any reduced reliance on biased media reports is reflected in voting decisions, the ultimate political outcome. Does biased coverage have less influence over voters than unbiased coverage? In this paper, we investigate these issues in the context of the role of newspaper endorsements in voting decisions. We begin by developing a simple econometric model in which voters have incomplete information over candidate quality and thus look to the media for guidance. Newspapers 
have better information than do voters but are potentially biased and may thus endorse candidates of relatively low quality if the bias is severe. Voters are rational and, when evaluating endorsements, attempt to filter out any such bias on the part of the media. The key insight of the model is that, if voters do filter out media bias, then endorsements for the Democratic candidate, say, from a left-leaning newspaper are less credible and should thus have less influence than a similar endorsement from a neutral or a right-leaning source.

We then test this prediction regarding media bias and the influence of the media on voting using information from daily survey data, which includes individual-level data on voting intentions as well as newspaper readership, in the months leading up to the 2000 and 2004 Presidential elections. These data are combined with newspaper-level endorsement information, which includes not only the name of the endorsed candidate but also the endorsement date, which facilitates a comparison of voter intentions and preferences after the endorsement to those of similar readers before the endorsement. Our measures of endorsement credibility are derived from a statistical model, which allows us to infer the ideological leanings of each newspaper as a function of its characteristics, which includes information on newspaper ownership as well as information regarding reader preferences over candidates prior to the publication of endorsements. Using these derived credibility measures, we show that endorsements are influential in the sense that readers are more likely to support the favored candidate after publication of the endorsement. Importantly, however, the credibility of the endorsement is the most important determinant of its influence. In particular, we show that influence is increasing in the credibility of the endorsement and that endorsements from extremely biased newspapers have little or no influence. Encouragingly, these baseline results are robust to several alternative specifications. Taken together, these results suggest that voters do attempt to learn from the media when choosing between candidates in elections but, at the same time, discount information from sources that are perceived to be politically biased.

The paper proceeds as follows. We next review the relevant literature on sources and measurement of media bias and the influence of the media on voting. We then develop an econometric model of voter learning from newspaper endorsements. After describing the data used in our empirical application, we provide details on the empirical implementation of the econometric model and describe the baseline empirical results and the robustness checks. The final section of the paper concludes. 


\section{Related Literature}

This paper is related to a large literature on the political economy of the media sector. Given the size of this literature, we focus here on its two most relevant branches: the sources and measurement of media bias and the influence of the media on voting decisions.

\subsection{Sources and Measures of Media Bias}

The theoretical literature in this area has focused primarily on the institutional determinants of media bias. According to the demand-side view, media outlets are primarily driven by profit motives, as opposed to political motives. In this case, bias may arise from the preferences of consumers of the media. Under the assumption that consumers prefer to consume news that confirms their prior beliefs, competition forces newspapers to differentiate themselves by moving to the ideological extremes (Mullainathan and Shleifer, 2005). Even if consumers prefer media outlets that deliver unbiased information, however, bias may emerge if readers use such reports to evaluate the quality of the information source. In this case, readers believe that outlets have better information if the reports conform to the prior beliefs of the reader (Gentzkow and Shapiro, 2006). A related idea is that, due to the increasingreturn-to-scale technology and their dependence on advertising revenue, media outlets may deliver more news to large groups and groups that are valuable to advertisers (Stromberg, 2004).

In addition to demand-side factors as a potential source, media bias may also reflect the preferences and career concerns of journalists (Baron, 2006), editors, or owners (Djankov et al., 2003). If the media plays a role in monitoring the behavior of incumbents, it is possible that government capture of the media sector may lead to distortions in news coverage (Besley and Prat, 2006). Puglisi (2006), Snyder and Stromberg (2008), Larcinese, Puglisi, and Snyder (2007) provide empirical support for this view of the media as a watchdog over the actions of incumbent politicians.

The literature has also made recent strides in terms of measuring the ideological orientation of different media outlets. Groseclose and Milyo (2005) provide a method for measuring media bias in the news stories of several major media outlets in the U.S. They arrive at their measure by counting the citations of think tanks in the media and then comparing 
the citations of think tanks by Republicans or Democrats in Congress. They find that, on average, outlets tend to be biased towards to the left. In a paper providing empirical support for the demand-side view of media bias, Gentzkow and Shapiro (2007) construct an index of media slant by comparing the language in newspapers to the language used by politicians in Congress. Their results suggest that newspaper slant is similar to the position that would be chosen by a profit-maximizing firm.

There is relatively little research into the political determinants of newspaper endorsements. The exceptions to this pattern include Ansolabehere et. al. (2006), who examine newspaper endorsements between 1940 and 2002. They document a trend away from strongly favoring Republicans in the early years of the sample towards favoring Democrats today. They also find that newspapers are much more likely to endorse incumbents today than in the past. Also, Kim (2008) provides evidence that newspaper endorsements are largely driven by owner preferences, rather than reader preferences.

\subsection{Media Influence}

Theoretically, the media may have persuasive effects, confirmative effects, or no effects on political behavior. According to Bray and Kreps (1987), on average, voters can filter out bias without being persuaded if voters are fully rational and media reports are continuous. On the other hand, if reports are binary, or "coarse", media reports may influence even fully rational voters; see, for example, Baron (2006). In addition, if voters are not fully rational, media may have persuasive effects on voting behavior (De Marzo, Vayanos, and Zwiebel, 2003).

The primary empirical challenge to detecting a causal media influence is the tendency for consumers to choose news outlets that share similar political perspectives. Several recent studies have made efforts in different ways to deal with this potential selection bias. Kaplan and Della Vigna (2007) identified the effect of Fox News on voting behavior by looking at the introduction of Fox News Channel in a town-level analysis. They found that Fox News convinced 3 to 28 percent of its viewers to vote Republican. Gerber, Karlan, and Bergan (2008) conducted a field experiment and found that subscriptions to the Washington Post increased the probability of voting for the Democratic candidate by eight percentage points in the 2005 Virginia gubernatorial election. Other studies have documented an effect of media 
exposure on voter turnout, including George and Waldfogel (2006) and Gentzkow (2006).

In terms of studies focusing on the impact of newspaper endorsements, Erikson (1976), using county-level data, finds that newspaper endorsements in the 1964 presidential elections increased the vote share of the endorsed candidate by five percentage points. Kahn and Kenney (2002) found significant positive effects of endorsements in U.S. Senate races on the comparative feeling thermometer score in National Election Survey data. Similarly, Druckman and Parkin (2005) find that endorsements have an effect on voting by using information from exit polls. Ladd and Lenz (2008) use changes in newspaper endorsements between the 1992 and 1997 elections in the United Kingdom and report that the persuasive effects of endorsements are large.

This paper contributes in several ways to this empirical literature on the influence of the media. First, we provide theoretical foundations for measuring the influence of the media on voting. Second, we attempt to address the tendency of consumers to access like-minded media outlets by collecting information on the endorsement date, which permits a pre-endorsement and post-endorsement comparison. Finally, as far as we are aware, our paper provides the first test of the idea that the influence of an endorsement should depend on its bias and its associated credibility.

\section{An Econometric Model of Voting and Endorsements}

In this section, we derive a simple econometric model of voter learning from newspaper endorsements. Given our empirical motivations, we keep the model simple and employ specific functional forms and distributional assumptions where necessary. It should be clear, however, that the basic logic of the model is robust to alternative modeling assumptions and does not rely on these specific functional forms.

The model consists of two candidates $(c \in\{D, R\})$ competing for election, a set of voters, indexed by $v$, and a set of newspapers, indexed by $n$. Candidates can be characterized by both their ideology $\left(i_{D}, i_{R}\right)$ as well as their quality $\left(q_{D}, q_{R}\right)$. Without loss of generality, we assume that ideology increases as candidate positions move further to the right; that is $i_{D}<i_{R}$. Voters can also be characterized by their ideology $\left(i_{v}\right)$, and, all else equal, prefer to elect the candidate with ideology closest to their own. Candidate quality, by contrast, is a characteristic that is valued by all voters and can be interpreted in a variety of ways, 
including political experience, integrity, or competence as an executive. More formally, we assume that voter $v$ receives the following payoff from candidate $c$ winning the election:

$$
U_{v c}=q_{c}-\frac{\omega}{2}\left(i_{v}-i_{c}\right)^{2}
$$

where $\omega$ represents the utility weight placed upon candidate ideology.

Regarding the information structure, we assume that voters know the ideological positions of the candidates but are uncertain over relative candidate quality, which is defined by $q=q_{D}-q_{R}$. In particular, we assume that initial priors over relative quality are normally distributed with mean $\mu$, which we normalize to zero, and a variance $\sigma_{q}^{2}$. Voters support the candidate who maximizes their expected utility.

Voters are assumed to read a single newspaper and potentially observe an endorsement from newspaper $n$ for either the Democrat $\left(e_{n}=1\right)$ or for the Republican $\left(e_{n}=0\right)$. Before observing an endorsement, voter $v$ supports the Democrat if his ideology is below the midpoint of the ideologies of the two candidates:

$$
E\left(U_{v d}\right)>E\left(U_{v r}\right) \Leftrightarrow i_{v}<\frac{i_{D}+i_{R}}{2}
$$

After observing an endorsement, voter $v$ supports the Democrat if his ideology is below a quality-adjusted threshold :

$$
E\left(U_{v d} \mid e_{n}\right)>E\left(U_{v r} \mid e_{n}\right) \Leftrightarrow i_{v}<\frac{i_{D}+i_{R}}{2}+\frac{E\left(q \mid e_{n}\right)}{\omega\left(i_{R}-i_{D}\right)}
$$

Thus, if voters update positively with regard to the relative quality of the Democrat, then the ideological threshold for supporting the Democrat is increased, or moves further to the right. By contrast, if voters update negatively with regard to the relative quality of the Democrat, then the ideological threshold for supporting the Democrat is decreased, or moves further to the left. In order to understand how voters update over quality following endorsements, as represented by $E\left(q \mid e_{n}\right)$, we next present a framework for newspaper endorsements.

During the campaign, newspapers receive information regarding candidate quality and make endorsements based on this information as well as their own ideological positions. In particular, newspapers are assumed to receive an unbiased signal over relative candidate quality:

$$
\theta_{n}=q+\varepsilon_{n}
$$


where $\varepsilon_{n}$ is the noise in the signal and is assumed to be normally distributed with mean zero and variance $\sigma_{\varepsilon}^{2}$. Rather than formally modelling the objectives and endorsement decisions of newspapers, we simply assume that each newspaper is associated with an exogenously given editorial position $\left(p_{n}\right)$ and endorses the Democrat if the (normalized) signal of quality exceeds this threshold:

$$
e_{n}=1\left[\frac{\theta_{n}}{\sqrt{\sigma_{q}^{2}+\sigma_{\varepsilon}^{2}}}>p_{n}\right]
$$

Thus, newspapers with higher values of $p_{n}$ lean further to the right and thus have a higher threshold for endorsing the Democratic candidate. We assume that voters know the editorial position of the newspaper $\left(p_{n}\right)$ as well as the quality of the newspaper's information $\left(\sigma_{\varepsilon}^{2}\right)$.

Returning to voter behavior, we can now evaluate how individuals attempt to infer quality from newspaper endorsements. As seen above, this inference is potentially complicated by the ideological position of newspapers. In addition, while the underlying information is continuous, the media report is discrete, and thus voters only learn that the information was above or below some newspaper-specific threshold. ${ }^{1}$ Accounting for any political bias by newspapers and the discrete nature of the endorsement, voters update over quality following an endorsement for the Democratic candidate as follows:

$$
E\left(q \mid e_{n}=1\right)=E\left[q \mid \theta_{n}>\sqrt{\sigma_{q}^{2}+\sigma_{\varepsilon}^{2}} p_{n}\right]=\beta \lambda_{d}\left(p_{n}\right)
$$

where $\beta=\sigma_{q}^{2} / \sqrt{\sigma_{q}^{2}+\sigma_{\varepsilon}^{2}}$ represents the voter's updating coefficient and is increasing in the degree of initial uncertainty $\left(\sigma_{q}^{2}\right)$ but is decreasing in the degree of noise in the signal $\left(\sigma_{\varepsilon}^{2}\right)$. Finally, $\lambda_{d}$ represents the credibility of an endorsement for the Democrat from newspaper $n$ and is defined by:

$$
\lambda_{d}\left(p_{n}\right)=\frac{\phi\left(p_{n}\right)}{1-\Phi\left(p_{n}\right)}
$$

and $\phi$ and $\Phi$ are the Normal density and distribution function, respectively. Given that $\lambda_{d}$ is monotonically increasing in $p_{n}$, we can say that, due to voter filtering of media bias, an endorsement for the Democrat, say, from a left-leaning newspaper, such as the New York Times, provides less information to voters than does an endorsement from a right-leaning

\footnotetext{
${ }^{1}$ A similar issue arises in Grossman and Helpman (1999), who focus on endorsements by interest groups, rather than media sources.
} 
newspaper, such as the Washington Times. ${ }^{2}$

Voters update in an analogous manner upon observing a Republican endorsement:

$$
E\left(q \mid e_{n}=0\right)=E\left[q \mid \theta_{n}<\sqrt{\sigma_{q}^{2}+\sigma_{\varepsilon}^{2}} p_{n}\right]=-\beta \lambda_{r}\left(p_{n}\right)
$$

where the credibility of a Republican endorsement can be written as follows:

$$
\lambda_{r}\left(p_{n}\right)=\frac{\phi\left(p_{n}\right)}{\Phi\left(p_{n}\right)}
$$

Similarly to the discussion of the credibility of Democratic endorsements, the credibility of Republican endorsements is decreasing in the degree of a newspaper's leaning to the right and such an endorsement from a left-leaning source provides more information to voters than does an endorsement from a right-leaning source.

Although we have taken editorial positions $\left(p_{n}\right)$ as exogenous here, in Appendix 1 we explore two models with endogenous editorial positions, both of which follow the theoretical literature on media bias. In a demand-side model, a monopoly newspaper attempts to maximize profits, and the value of information to a representative consumer depends upon the editorial position. In this case, the newspaper optimally slants its coverage towards reader preferences. In a supply-side model, by contrast, newspapers have ideological preferences and attempt to increase the electoral prospects of their preferred party. In this case, editorial positions reflect owner preferences.

\section{Data}

In order to estimate the influence of newspaper endorsements, we use voter reactions to endorsements as captured in daily survey data, which are provided by the National Annenberg Election Surveys 2000 and 2004. This survey employs a rolling cross-section design in which hundreds of voters were polled on a daily basis in the months leading up to the election. For the purposes of our analysis, we use information from these data on voting intention, voting decision, favorability of candidates and the newspaper read most often. The vote intention question regarding the choice between Gore and Bush for 2000 presidential election was asked between December 14, 1999 and election day. The exact wording is the following: "Thinking about the general election for president and candidates were George W. Bush, the

\footnotetext{
${ }^{2}$ For the result regarding the monotonicity of the Mills ratio, see Heckman (1979).
} 
Republican, and Al Gore, the Democrat, who would you vote for?" Respondents may choose to answer "Republican, Democrat, other, would not vote for president, or don't know". After election day, respondents were asked which candidate they voted for if voted. ${ }^{3}$ The wording in the 2004 survey is similar to that in 2000, although voters may also choose to vote for Nader.

Information regarding the dates of newspaper endorsements and endorsed candidates is derived from several different sources, including the website Democracy in Action and various newspaper archives (Lexis-Nexis, Factiva, and the Associated Press). ${ }^{4}$ As shown in Figure 1 , there is substantial variation in the timing of newspaper endorsements. Most newspapers published their endorsements in the editorial pages during the weekend. While many newspapers made endorsements in the weekend just before the election, some newspapers made their intentions known earlier.

In order to estimate newspaper editorial positions, which are unobserved by the econometrician, we rely on information on newspaper ownership and political preferences of readers. Kim (2008) provided data on group ownership. Readers' preference is based on vote intention of newspaper readers prior to the publication of endorsements. As a robustness check, we also use preferences of residents in the newspaper market to measure preferences of potential readers, where newspaper markets are defined as the area in which most of its readers reside.

Small newspapers, defined as those with less than ten readers in the data, and newspapers that did not make an endorsement are excluded from the sample. After dropping these observations, we have 166 newspapers in 2000, 212 newspapers in 2004, and 32,014 individuals in the sample, of which twelve percent were surveyed after publication of the endorsement. Summary statistics are presented in Table 1.

\section{Empirical Application}

\subsection{Econometric implementation}

\footnotetext{
${ }^{3}$ Given that the data do not have precise information on the timing of voting among early voters, we do not know whether or not the vote choice was made before or after the endorsement. Given this limitation, we thus exclude early voters from the sample.

4 The Democracy in Action webiste of newspaper is available at http://www.gwu.edu/ action/natendorse5.html.
} 
To further develop the econometric model, we assume that voter ideology can be written as a function of observed voter characteristics $\left(X_{v}\right)$, which includes a constant term, a set of fixed effects and unobserved characteristics:

$$
i_{v}=\theta X_{v}+\eta_{t}+\eta_{n}+\eta_{v t}
$$

where $\theta$ is a vector of parameters to be estimated, $\eta_{t}$ is a time fixed effect, $\eta_{n}$ is a newspaper fixed effect, and $\eta_{v t}$ is unobserved by the econometrician. For tractability, we assume that $\eta_{v t}$ is uniformly distributed, which leads to the linear probability model. In addition, we assume that newspaper editorial positions can be expressed as a function of newspaper characteristics:

$$
p_{n}=\gamma Z_{n}
$$

Using these parameterizations, we can summarize the two-equation model as follows:

$$
\begin{aligned}
& \operatorname{Pr}(\text { endorse } \mathrm{D})=1-\Phi\left(\gamma Z_{n}\right) \\
& \operatorname{Pr}(\text { vote D })=\beta \operatorname{After}_{n t}\left[e_{n} \lambda_{d}\left(\gamma Z_{n}\right)-\left(1-e_{n}\right) \lambda_{r}\left(\gamma Z_{n}\right)\right]-\theta X_{v}-\eta_{t}-\eta_{n}
\end{aligned}
$$

where After $_{n t}$ is a dummy variable indicating whether or not the endorsement by newspaper $n$ had been published by date $t$. Note that the voting equation depends upon the vector of parameters from the endorsement equation $(\gamma)$, which is unobserved by the econometrician, and we thus estimate the model in two stages. In the first-stage, we estimate a Probit model in which newspaper endorsement decisions are related to newspaper characteristics $\left(Z_{n}\right)$. With the estimated parameters $(\widehat{\gamma})$ from this first stage, we can then compute the Mills ratios $\lambda_{d}\left(\widehat{\gamma} Z_{n}\right)$ and $\lambda_{r}\left(\widehat{\gamma} Z_{n}\right)$, which we use in the second-stage voting equation. Given that this second stage includes a generated regressor, we compute the standard errors using bootstrapping techniques. ${ }^{5}$

\subsection{Baseline Results}

Table $2 \mathrm{~A}$ reports results from estimation of the first-stage endorsement equation. Following the literature on media bias and the discussion of editorial positions in Appendix 1, we include the preferences of owners as a supply-side measure as well as the preferences of readers

\footnotetext{
${ }^{5}$ In particular, we draw samples with replacement from the underlying set of newspapers and also independently draw samples with replacement from the underlying set of voters. The standard errors are based upon 200 replications.
} 
as a demand-side measure. To avoid potential endogeneity problems, we use the fraction of readers supporting the Democrat prior to the publication of the endorsement. As shown, the preferences of readers has a strong and statistically significant effect on newspaper endorsement decisions. To capture the preferences of owners, we include dummy variables for group-owned newspapers. ${ }^{6}$ As shown, newspapers that are owned by Cox Newspapers, Gannett, Knight Ridder, McClatchy Newspapers, and the New York Times Company are more likely to endorse Democratic candidates. These results are consistent with Kim (2008), who shows that four out of five of these groups tend to contribute more to Democratic candidates than to Republican candidates. The results also demonstrate that newspapers were more likely to endorse the Democrat during the 2004 campaign, relative to 2000 campaign.

Using these coefficients, we can then compute the predicted probability of an endorsement for either the Democrat or the Republican, and these predicted probabilities are then converted into credibility measures. As shown in Table 3, there is significant variation in the predicted probability of an endorsement for the Democrat in 2000 among the top 20 newspapers in the United States. At one extreme, the Dallas Morning News is predicted to endorse the Democrat with just 17 percent probability, reflecting the Republican orientation of local readers. At the other extreme, the New York Times is predicted to endorse the Democrat with 90 percent probability, reflecting the left-leaning predispositions among readers as well as its ownership by the New York Times Company. According to our estimates, the newspaper among the top 20 with the least bias is the Washington Post, which is predicted to endorse the Democrat with 54 percent probability.

Before turning to the second-stage estimates, we first provide graphical evidence regarding the influence of endorsements. To provide a simple test for whether or not endorsements are influential on average, Figure 2 depicts trends in support for the Democratic candidate among readers separately for newspapers endorsing the Democrat and for newspapers endorsing the Republican in the two weeks surrounding the endorsement. As shown, for all newspapers, there does seem to be a slight widening in the gap between readers of Democratendorsing newspapers and readers of Republican-endorsing newspapers after publication of the endorsement. The effect is relatively small, however, and is somewhat difficult to detect. As evidence regarding the prediction that endorsement influence depends upon its credibility,

\footnotetext{
${ }^{6}$ We define a group as a company owning more than 10 newspapers. The default category is newspapers not owned by groups.
} 
we next split the sample into readers of newspapers with high-credibility endorsements and readers of newspapers with low-credibility endorsements. As shown in Figure 3, which focuses on high credibility, or surprising, endorsements, there appears to be an immediate and significant effect of the endorsement on reader voting intentions. In Figure 4, by contrast, which focuses on low-credibility, or unsurprising endorsements, the effect is again small and difficult to visually detect. These results suggest that high credibility endorsements do have more influence than do low-credibility endorsements, and we turn next to a more formal econometric examination of this hypothesis.

As shown in column 1 of Table 2B, which presents our second-stage results based upon our first-stage estimates of credibility, we find support for the idea that endorsement credibility is a key determinant of the influence of the endorsement, as the coefficient on our credibility measure is positive and statistically significant. Regarding the other controls, we also find that voters who are older or black are more likely to vote for Democrats and voters who complete high school, relative to high school dropouts, who are male, who attend religious services or consider themselves born-again Christians are more likely to vote for the Republican.

To provide a sense of the magnitude of this effect of endorsements and endorsement credibility, the final column of Table 3 provides our implied estimates of the influence of endorsements in the top 20 newspapers in the United States during the 2000 campaign. As shown, the least credible endorsements were for Gore from the New York Times and for Bush from the Dallas Morning News. According to the logic of our model, the higher probability of endorsing Gore by the New York Times, for example, can be interpreted as having a lower standard in terms of information regarding the quality of Gore, relative to Bush. Thus, these low-credibility endorsements from the New York Times and the Dallas Morning News convinced less than one percent of their readers to switch their allegiance to the endorsed candidate. The endorsements with the largest effect, by contrast, came from the Denver Post and the Chicago Sun Times, both of which had surprising endorsements. According to our estimates, these endorsements convinced about 3 percent of readers to switch their allegiance to the endorsed candidate. Interestingly, both of these newspapers switched their endorsements in 2004, when the Chicago Sun Times endorsed Kerry and the Denver Post endorsed Bush. This pattern is consistent with our characterization of these endorsements in 2000 as unusually credible and surprising. 
Table 4 provides estimates of the effect of endorsements across all newspapers. As shown, according to our estimates, the Democratic vote share among readers would have been about 2.2 percent higher in 2000 and 1.7 percent higher in 2004 had all newspapers endorsed the Democrat. If all newspapers had endorsed Bush in 2000 and 2004, by contrast, the Democratic vote share among newspaper readers would have been 2.6 percent lower in 2000 and 3.1 percent lower in 2004; again these numbers are slightly lower for vote shares among all voters. Taken together, the difference between all Republican and all Democratic endorsements is almost 5 percent among newspaper readers in both 2000 and 2004. Given that three-quarters of the sample reports reading a newspaper, this suggests that the net effect on all voters would have been about 4 percent in both 2000 and 2004 under the assumption that non-readers were unaffected. ${ }^{7}$

One limitation of the baseline results in column 1 of Table $2 \mathrm{~B}$ is that they combine both the effects of endorsements and the credibility of endorsements into a single coefficient. One could interpret the credibility measures as econometric weights, where the estimator places more weight on high credibility endorsements and less weight on low credibility endorsements. Given this interpretation, we next estimate an unweighted model as a first attempt to separate these two effects. In this model, we implicitly assume that voters do not filter out bias, and, in this case, newspaper editorial positions do not matter, and every endorsement has the same credibility and thus the same influence. In particular, we estimate a linear probability model in which we include only the endorsement dummy variable $\left(e_{n}\right)$ :

$$
\operatorname{Pr}(\text { vote } \mathrm{D})=\beta \operatorname{After}_{n t}\left(2 e_{n}-1\right)-\theta X_{v}-\eta_{t}-\eta_{n}
$$

As shown in column 2 of Table 2B, the coefficient is small and statistically insignificant, suggesting that only high credibility endorsements have influence and that, on average, endorsements have only a small effect.

To explore this issue further, we also estimate a specification in which we separately control for the credibility of the endorsement and a simple endorsement dummy:

\footnotetext{
7 These percentages are somewhat higher than other estimatates of newspaper readership. In a survey conducted by Pew Research Center, $65 \%$ of respondents said that they read newspapers. According the circulation data published in Editor and Publisher Year Book, the circulation rate is around 20\% in the United States. This figure is not directly comparable to our survey data, however, given that there are three people per household on average, and a newspaper may be read by more than one member of the household.
} 


$$
\operatorname{Pr}\left(\operatorname{vote~D}_{)}=\tau \operatorname{After}_{n t}\left[e_{n} \lambda_{d}\left(p_{n}\right)-\left(1-e_{n}\right) \lambda_{r}\left(p_{n}\right)\right]+\alpha \operatorname{After}_{n t}\left(2 e_{n}-1\right)\right]-\theta X_{v}-\eta_{t}-\eta_{n}
$$

If filtering is complete, as is assumed in our baseline specification, then the credibilityweighted measure should have all of the explanatory power and $\tau=\beta$ and $\alpha=0$. If voters do not filter, by contrast, then the credibility measure should have no effect $(\tau=0)$ and the effect of the endorsement, which is common across newspapers, is summarized by the coefficient on the simple endorsement dummy $(\alpha>0)$.

Whether or not voters filter out bias has important implications for whether or not the media can systematically influence voters and favor one party over another. To see this, define the ex-post influence of the endorsement as follows:

$\Delta=\operatorname{Pr}($ vote $\mathrm{D} \mid$ After $=1)-\operatorname{Pr}($ vote $\mathrm{D} \mid$ After $=0)=\tau\left[e_{n} \lambda_{d}\left(p_{n}\right)-\left(1-e_{n}\right) \lambda_{r}\left(p_{n}\right)\right]+\alpha\left(2 e_{n}-1\right)$

The ex-ante influence, before the endorsement decision is made, is then defined naturally by $E(\Delta)$. Given the definitions of the Mills ratio and the fact that $\operatorname{Pr}\left(e_{n}=1\right) \lambda_{d}\left(p_{n}\right)=\operatorname{Pr}\left(e_{n}=\right.$ 0) $\lambda_{r}\left(p_{n}\right)=\phi\left(p_{n}\right)$, the first term vanishes when taking expectations, and we have that:

$$
E(\Delta)=2 \alpha\left[\operatorname{Pr}\left(e_{n}=1\right)-0.5\right]
$$

Thus, in the absence of filtering $\alpha>0$, biased media outlets have systematic influence, and the Democratic candidate is advantaged if the outlet is biased to the left $\left(\operatorname{Pr}\left(e_{n}=1\right)>0.5\right)$ and likewise for the Republican candidate if the outlet is biased to the right $\left(\operatorname{Pr}\left(e_{n}=1\right)<\right.$ 0.5 ). With complete filtering, by contrast, $\alpha=0$, and the media cannot have systematic influence due to the sophistication on the part of voters.

As shown in column 3 of Table 2B, our results support the notion of complete filtering, relative to no filtering, as the coefficient on the simple endorsement dummy variable is now negative and statistically insignificant. The coefficient on the credibility measure, by contrast, is positive, larger in magnitude than that in column 1, and is highly statistically significant. Taken together, these results support the view of complete filtering over that of no filtering and suggest that voters are sufficiently sophisticated such that any media bias cannot systematically benefit one party over another. 


\subsection{Alternative Explanations}

In Tables 5 and 6, we explore three alternative explanations for our results. The first alternative explanation involves differential trends among readers of different types of newspapers. For example, if Republican readers become more likely to support the Republican candidate during the campaign and Democratic readers become more likely to support the Democratic candidate, then, under the assumption that newspapers with Republican readers tend to endorse Republican candidates, we would expect more readers to move towards the endorsed candidate after the endorsement even if the endorsement has no influence at all. While our baseline model includes day fixed effects, which account for national trends, we have no controls for local trends. We address this issue in two ways. First, in column 1 of Table 5, we present results that include newspaper-specific trends. This adds a large number of additional parameters to be estimated, and, as shown, the key coefficient is now only significant at the 90-percent level. In the second column, we allow for different trends by voter ideology, which we measure using self-reported ideology. In particular, we allow for separate trends for each of five ideology categories: very conservative, conservative, moderate, liberal, very liberal. As shown, the results are similar to those in the baseline specification.

A second alternative explanation for our baseline result involves differential responsiveness of readers of different newspapers. For example, a liberal newspaper may tend to have mostly very liberal readers and thus very few readers who would switch from supporting the Republican to supporting the Democrat following an endorsement for the Democrat. On the other hand, more moderate newspapers may have a large fraction of undecided readers who could be influenced by an endorsement for the Democrat. Then, we would expect an endorsement for the Democrat by the moderate newspaper to have more influence than a similar endorsement by the liberal newspaper even if voters do not filter out media bias. To address this issue, we next use the voter ideology measures described above to compare responses to endorsements by similar pools of voters who happen to read different newspapers. In particular, in column 3 of Table 5 , we exclude those readers least likely to be influenced by an endorsement, very liberal and very conservative voters, and find that the result is similar to the baseline. Next, in column 4, we focus exclusively on moderate readers, which is less than half of the sample. As shown, the effect is much stronger here than the baseline result and remains significant at the 95-percent level.

A third alternative explanation involves the timing of endorsements. For example, sup- 
pose that a candidate visits a city on a campaign stop and that this visit attracts both voters and the endorsement from the local newspaper shortly after the visit. In this case, we would expect to see support for the endorsed candidate rise after the endorsement even if the endorsement itself has no influence. To address this issue, we examine the timing of newspaper endorsements. In particular, Table 6 provides the endorsement dates in both 2000 and 2004 for 69 newspapers in our sample that endorsed on one of the three Sundays preceding the election in both 2000 and 2004. If newspapers tend to endorse on the same day across election cycles, then it seems unlikely that the endorsements reflect high frequency events occurring in the city. As shown, there does seem to be some persistence, with about 45 percent of newspapers endorsing on the same date in both 2000 and 2004. Interestingly, the bulk of the exceptions, roughly 30 percent of the observations, involved newspapers that endorsed two Sundays before the election in 2000 but three Sundays before the election in 2004. This trend towards slightly earlier endorsements likely reflects the shift towards early voting in 2004 (Strupp, 2004). Indeed, about one-quarter of these newspapers are located in Florida, which introduced early voting in 2004 . We find only a few cases with dramatic differences in the timing of endorsements, such as one newspaper endorsing three Sundays before the election in 2004 and one Sunday before the election in 2000. Although we cannot completely

rule out this third alternative explanation for our results, these findings do suggest that the timing of endorsements follow relatively regular patterns.

\subsection{Alternative credibility measures}

In this section, we provide results from alternatively credibility measures. Column 1 of Table

7 provides results from an alternative measure based upon the surprise of the endorsement. This specification, which does not rely on the underlying assumptions regarding candidate quality, is given as follows:

$$
\operatorname{Pr}\left(\operatorname{vote}^{\mathrm{D}}\right)=\tau \operatorname{After}_{n t}\left[e_{n} \Phi\left(\gamma Z_{n}\right)-\left(1-e_{n}\right)\left(1-\Phi\left(\gamma Z_{n}\right)\right)\right]-\theta X_{v}-\eta_{t}-\eta_{n}
$$

Recalling that the probability of an endorsement for the Republican is given by $\Phi\left(\gamma Z_{n}\right)$, this measure captures the notion that the larger this probability, the greater the degree of influence for a Democratic endorsement. Likewise, the influence of an endorsement for the Republican should be increasing in the probability of an endorsement for the Democrat, 
which is given by $\left(1-\Phi\left(\gamma Z_{n}\right)\right)$. As shown, the coefficient on this alternative credibility measure has the expected positive sign and remains statistically significant.

Column 2 uses a measure of credibility based upon the historical endorsement patterns of newspapers. Note that with a sufficiently long panel of newspaper endorsements, one can approximate the probability that newspaper $n$ endorses the Democrat $\left(1-\Phi\left(p_{n}\right)\right)$ by the frequency with which the newspaper actually endorses the Democrat $\left(f_{n}\right)$. Inverting this probability, we can then uncover the newspaper's editorial position as follows:

$$
p_{n}=\Phi^{-1}\left(1-f_{n}\right)
$$

Finally, this measure of editorial position can be plugged into the credibility measures $\lambda_{d}\left(p_{n}\right)$ and $\lambda_{r}\left(p_{n}\right)$. To implement this idea, we use historical endorsement data from Editor and Publisher as provided by Kim (2008). These data include endorsements in the 10 Presidential elections between 1960 and 1996. Note that the response rate to the Editor and Publisher survey is relatively low, and the median newspaper has endorsement information for only 5 out of the 10 elections. For the 2000 endorsements, we calculate $f_{n}$ as the fraction of endorsements for the Democrat between 1960 and 1996, and, for the 2004 endorsements, we calculate $f_{n}$ as the fraction of endorsements for the Democrat between 1960 and 2000. For newspapers that exclusively endorse one party in the historical data $\left(f_{n}=0\right.$ or $\left.f_{n}=1\right)$, we cannot calculate editorial positions as outlined above, and we thus exclude these cases from the analysis. As shown in column 2, the coefficient is quite similar to that in the baseline specification and remains significant at the 90-percent level. Given the incomplete response rate, we focus in column 3 on the set of newspapers with a relatively complete history, those with more than 5 endorsements in the Editor and Publisher data, and, as shown, the results are stronger and the key coefficient is statistically significant at the 95-percent level.

\subsection{Additional Robustness Checks}

Table 8 provides a series of additional robustness checks of the baseline results. Column 1 presents the results of the specification without the constraint that the effects of Democratic endorsements have equal and opposite signs to those of Republican endorsements. The results demonstrate that the effect of Democratic endorsements has the expected positive sign, while the effect of Republican endorsements has the expected negative sign. While neither is statistically different from zero, they are statistically different from one another at 
conventional levels. In column 2, we allow the key coefficients to vary across the 2000 and 2004 elections. While both coefficients have the expected positive sign, only the coefficient on the 2004 credibility measure is statistically different from zero. This could reflect the fact that Bush was an incumbent in 2004, and newspapers may have thus obtained better information regarding his quality.

Column 3 uses an alternative measure of readers preferences in the first stage, that of potential, rather than actual readers. In particular, we use the fraction of residents in the newspaper's market that support the Democrat prior to the endorsement. On the one hand, this seems a more natural measure since newspapers may set editorial positions in order to maximize readership. On the other hand, in cities with sufficient scale to support multiple newspapers, the market is often segmented into left-leaning and right-leaning newspapers, as is the case in Washington DC, where left-leaning readers choose the Washington Post and right-leaning readers choose the Washington Times. It is also possible that some voters are natural newspaper readers and others are not, and the newspaper may attempt to maximize the surplus of readers in order to charge a higher price or to include additional advertising material. Thus, in some cases, the preferences of readers may be a more natural proxy for editorial positions. In any event, we provide this measure of preferences of residents as an alternative measure of voter preferences. In the first stage, which is not reported here, the market-level preference measure remains positive and statistically significant. In the second stage, the coefficient on endorsement credibility remains positive but is statistically insignificant.

The final robustness check uses information on readership intensity. In the data, readers were asked how many days per week they read the newspaper. It seems reasonable to assume that those voters reporting to have read the newspaper seven days per week, which is roughly half of the sample of newspaper readers, are more likely to be exposed to the endorsement, relative to low-intensity readers, defined as those reading less than seven days per week. As shown in column 4, which restricts the sample to those reading seven days per week, the coefficient is larger than in the baseline results and remains statistically significant at the 90 percent level. Taken together, the robustness checks reported here tend to support the baseline results and provide further evidence that readers are responsive to credible endorsements. 


\section{Conclusion}

In this paper, we have investigated the influence of newspaper endorsements on voting patterns in the 2000 and 2004 U.S. Presidential elections. We first develop a simple econometric model in which voters are uncertain over candidate quality and turn to newspaper endorsements for information about the candidates. Newspapers, however, are potentially biased in favor of one of the candidates and voters thus rationally account for the credibility of any endorsements. Our primary finding is that endorsements are influential in the sense that voters are more likely to support the recommended candidate after publication of the endorsement. The degree of this influence, however, depends upon the credibility of the endorsement. In this way, endorsements for the Democratic candidate from left-leaning newspapers are less influential than are endorsements from neutral or right-leaning newspapers and likewise for endorsements for the Republican candidate. These results suggest that voters are sophisticated and attempt to filter out any bias in media coverage of politics. 


\section{Appendix: Endogenous Editorial Positions}

We have considered two theoretical models with endogenous editorial positions. The first model follows a literature on demand-side bias. Newspapers are assumed to be profitmaximizing firms and attempt to maximize the value of information to a representative consumer with ideology $i_{v}$. Among other interpretations, this objective could reflect a desire to charge a maximal price or to bundle the maximum amount of advertising. Finally, we assume that newspapers can commit to an editorial position. Without loss of generality, consider a left-leaning voter $\left[i_{v}>\left(i_{R}+i_{D}\right) / 2\right]$. The value of information in this case $(V)$ is the possibility of an endorsement for $R$ :

$$
\begin{aligned}
V & =\operatorname{Pr}\left(e_{n}=0\right) E\left[U_{v R}-U_{v D} \mid e_{n}=0\right] \\
& =\Phi\left(p_{n}\right)\left[\frac{\omega}{2}\left(i_{v}-i_{D}\right)^{2}-\frac{\omega}{2}\left(i_{v}-i_{R}\right)^{2}\right]+\beta \phi\left(p_{n}\right)
\end{aligned}
$$

The first term is negative and represents the cost of voting against one's prior. The second term represents the value of information. In this case, it is straightforward to show that the editorial position that maximizes the value of information to the representative consumer is linearly increasing in the ideology of the voter $\left(i_{v}\right)$ :

$$
p_{n}^{*}=\frac{\omega}{2 \beta}\left[2\left(i_{R}-i_{D}\right) i_{v}+\left(i_{D}^{2}-i_{R}^{2}\right)\right]
$$

This result is similar to that in Suen (2004), who examines similar issues in the context of a binary quality measure.

The second model follows a literature on supply-side bias. Newspaper owners are citizens with ideological preferences $\left(i_{n}\right)$ and wish to manipulate voting decisions of a representative voter. We look for an informative equilibrium in which the newspaper endorses according owner preferences, and the voter chooses to follow the endorsement even if it requires voting against his prior. In this case, the newspaper prefers the Democrat after receiving the signal if:

$$
E\left(q \mid \theta_{n}\right)-\omega\left(i_{R}-i_{D}\right) i_{n}-\frac{\omega}{2}\left(i_{D}^{2}-i_{R}^{2}\right)>0
$$

Using the fact that $E\left(q \mid \theta_{n}\right)=\frac{\sigma_{q}^{2}}{\sigma_{q}^{2}+\sigma_{\epsilon}^{2}} \theta_{n}$ under Bayesian updating, we have that the editorial position is thus increasing in the ideology of the editor $\left(i_{n}\right)$ :

$$
p_{n}=\frac{\omega}{2 \beta}\left[2\left(i_{R}-i_{D}\right) i_{n}+\left(i_{D}^{2}-i_{R}^{2}\right)\right]
$$


In order for this to be an informative equilibrium, the representative voter must follow the endorsement even if it goes against his prior. This requires that the newspaper's information is of sufficiently high quality and that the preferences of the reader and owner are sufficiently aligned. 


\section{References}

Ansolabehere, Stephen and Rebecca Lessem and James Snyder, "The Orientation of Newspaper Endorsements in US Elections, 1940-2002," Quarterly Journal of Political Science, 1(4): 393-404, 2006.

Baron, David, "Persistent Media Bias," Journal of Public Economics 90(1-2): 1-36, 2006.

Besley, Timothy and Andrea Prat, "Handcuffs for the Grabbing Hand? Media Capture and Government Accountability," American Economic Review, 96(3):720-736, 2006.

Bray, Margaret and David M. Kreps, "Rational Learning and Rational Expectations," Arrow and the Ascent of Modern Economic Theory, 597-625, 1987.

DellaVigna, Stefano. and Ethan Kaplan, "The Fox News Effect: Media Bias and Voting," Quarterly Journal of Economics, 122: 1187-1234, 2007.

DeMarzo, Peter M., Dimitri Vayanos and Jefferey Zweiebel, "Persuasion Bias, Social Influence, and Unidimensional Opinions," Quarterly Journal of Economics, 118(3):909-968, 2003.

Djankov, Simeon, Caralee McLiesh, Tatiana Nenova, and Andrei Shleifer, "Who Owns the Media", The Journal of Law and Economics, 46:2, 341-382, 2003.

Druckman, James and Michael Parkin, "The Impact of Media Bias: How Editorial Slant Affects Voters" Journal of Politics, 64(7), 1030-1049, 2005.

Erikson, R.S., "The Influence of Newspaper Endorsements in Presidential Elections: The Case of 1964," American Journal of Political Science, 20(2): 207-233, 1976.

Grossman, Gene M. and Helpman, Elhanan, "Competing for Endorsements," American Economic Review, 89(3): 501-24, 1999.

Gentzkow, Matthew, "Television and Voter Turnout", Quarterly Journal of Economics, 121(3), 931-972, 2006.

Gentzkow, Matthew and Jess M. Shapiro, "Media Bias and Reputation," Journal of Political Economy, 114(2): 280-316, 2006. 
Gentzkow, Matthew and Jess M. Shapiro, "What Drives Media Slant? Evidence from U.S. Daily Newspapers." Working paper, University of Chicago, 2007.

George, Lisa, and Joel Waldfogel, "The New York Times and the Market for Local Newspapers", American Economic Review, 96(1), 435-447, 2006.

Gerber, Alan, Karlan, Dean S. and Bergan, Daniel, "Does The Media Matter? A Field Experiment Measuring the Effect of Newspapers on Voting Behavior and Political Opinions," forthcoming, American Economic Journal: Applied Economics, 2008.

Groseclose, Tim and Jeffrey Milyo, "A Measure of Media Bias," Quarterly Journal of Economics, 120(4): 1191-1237, 2005.

Heckman, James, "Sample Selection Bias as a Specification Error," Econometrica, 47(1): 153-161, 1979.

Kahn, Kim and Patrick Kenney, "The Slant of the News: How Editorial Endorsements Influence Campaign Coverage and Citizens' Views of Candidates", American Political Science Review, 96(2), 381-394, 2002.

Kim, Chisoo, "Group Ownership and Newspaper Endorsements." Working paper, Brown University, 2008.

Ladd, Jonathan, and Gabriel Lenz, "Exploiting a Rare Shift in Communication Flows to Document Media Effects: the 1997 British Election", working paper, MIT, 2008.

Larcinese, Valentino, Riccardo Puglisi, and James Snyder, "Partisan Bias in Economic News: Evidence on the Agenda-Setting Behavior of U.S. Newspapers", NBER working paper 13378, 2007.

Mullainathan, Sendhil and Andrei Shleifer, "Market for News," American Economic Review 95(4): 1031-1053, 2005.

Pew Research Center, "Trends: 2005", 2005.

Puglisi, Riccardo, "Being the New York Times: the Political Behavior of a Newspaper", working paper, London School of Economics, 2006. 
Snyder, James, and David Stromberg, "Press Coverage and Political Accountability", NBER working paper 13878, 2008.

Stromberg, D., "Mass Media Competition, Political Competition, and Public Policy," Review of Economic Studies 71(1): 265-284, 2004.

Strupp, J., "Trend of Early Voting Means Earlier Newspaper Endorsements", Editor and Publisher, October 11, 2004.

Suen, W., "The Self Perpetuation of Biased Beliefs," Economic Journal 114: 377-396, 2004. 
Figure 1: Dates of Newspaper Endorsements in 2000 and 2004

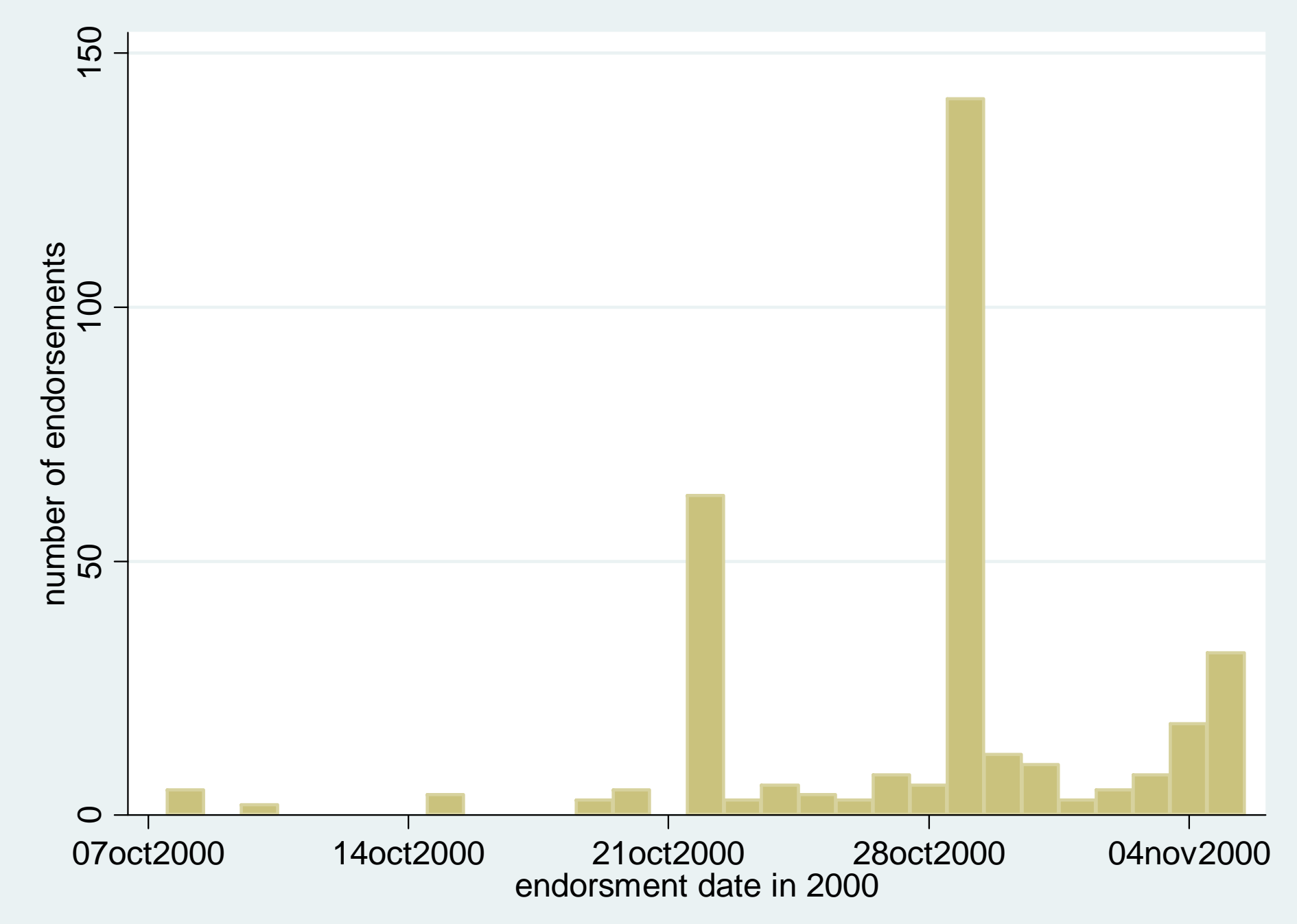




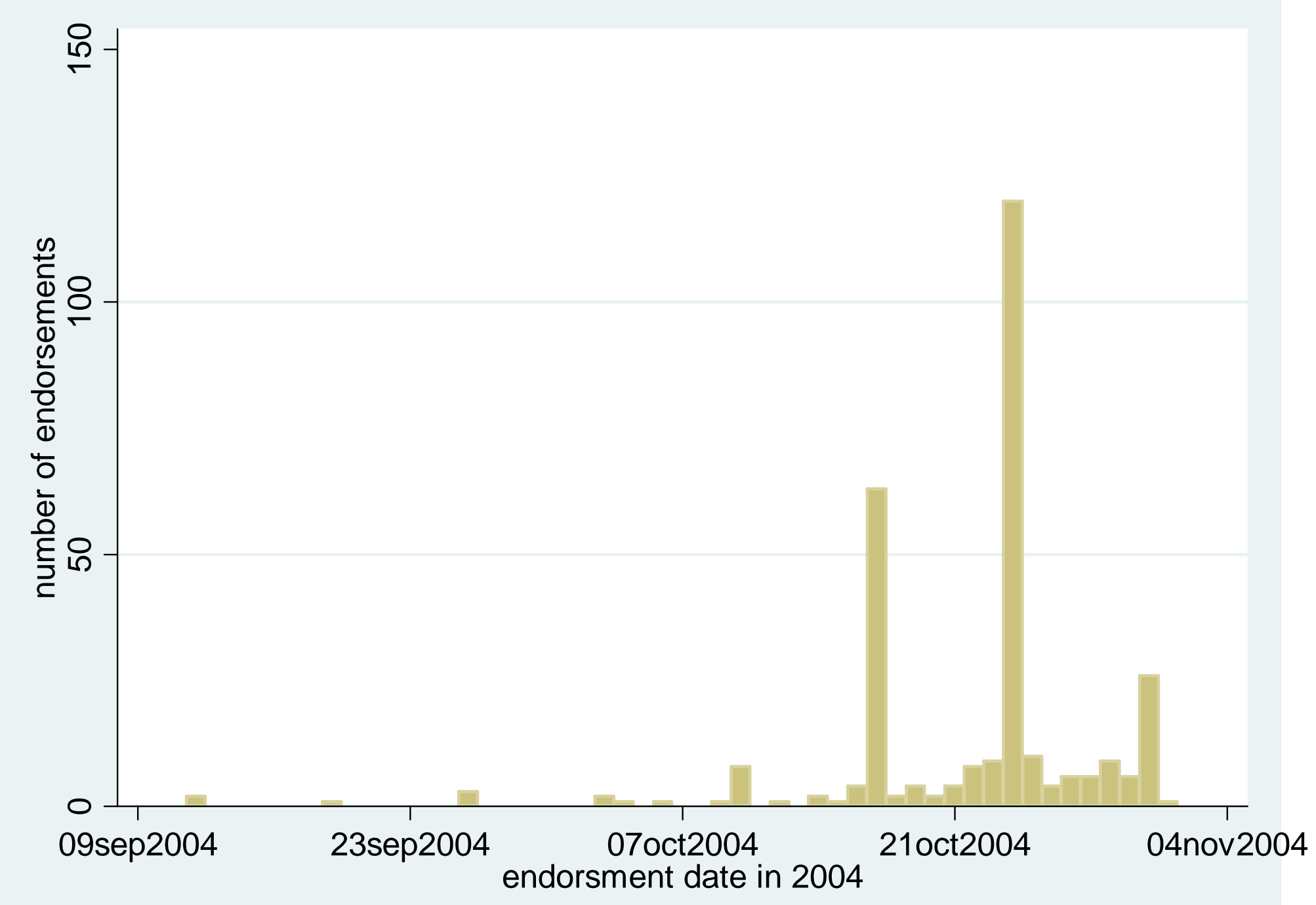




\section{Figure 2: Endorsements and Voting}

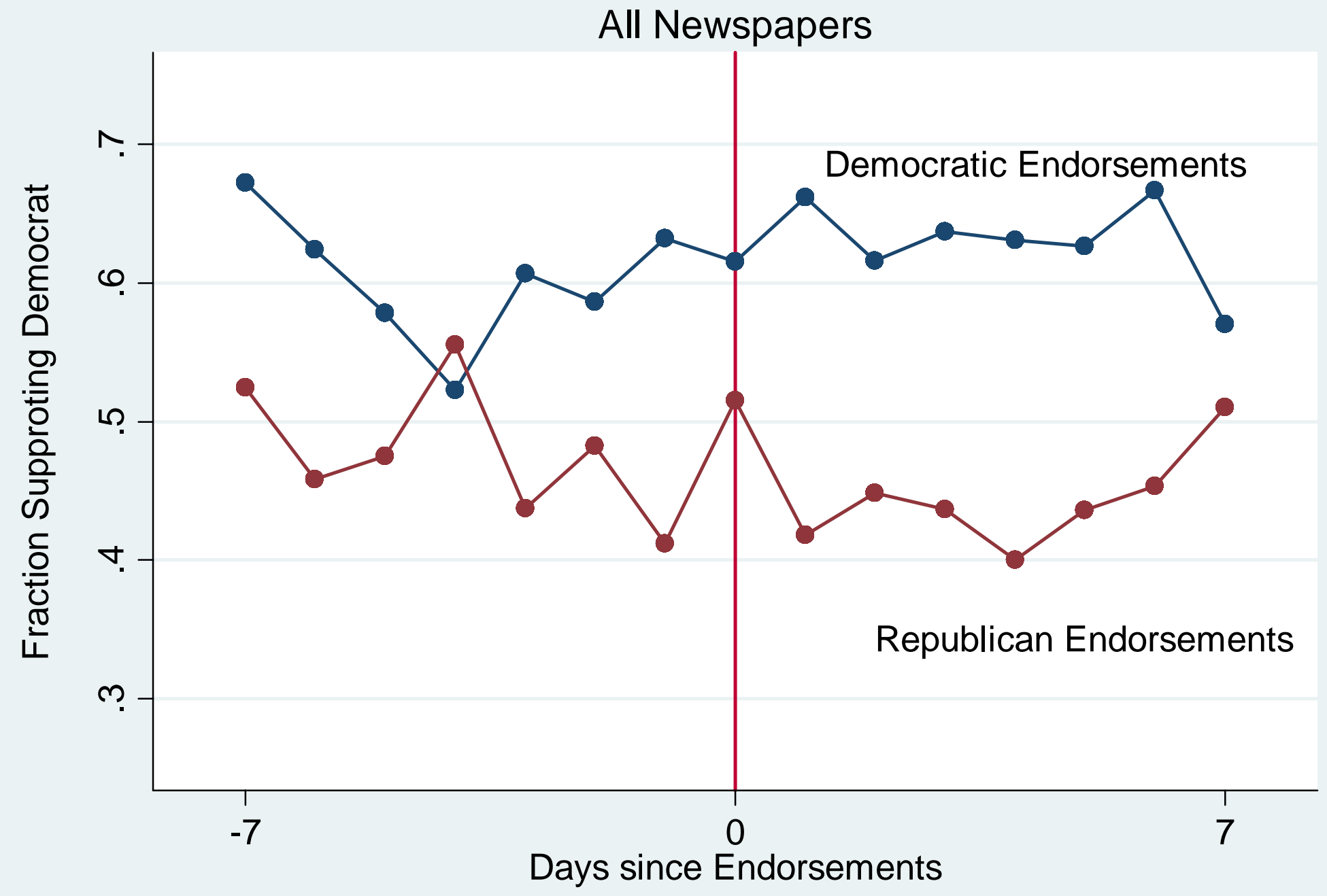


Figure 3: High-Credibility Endorsements and Voting

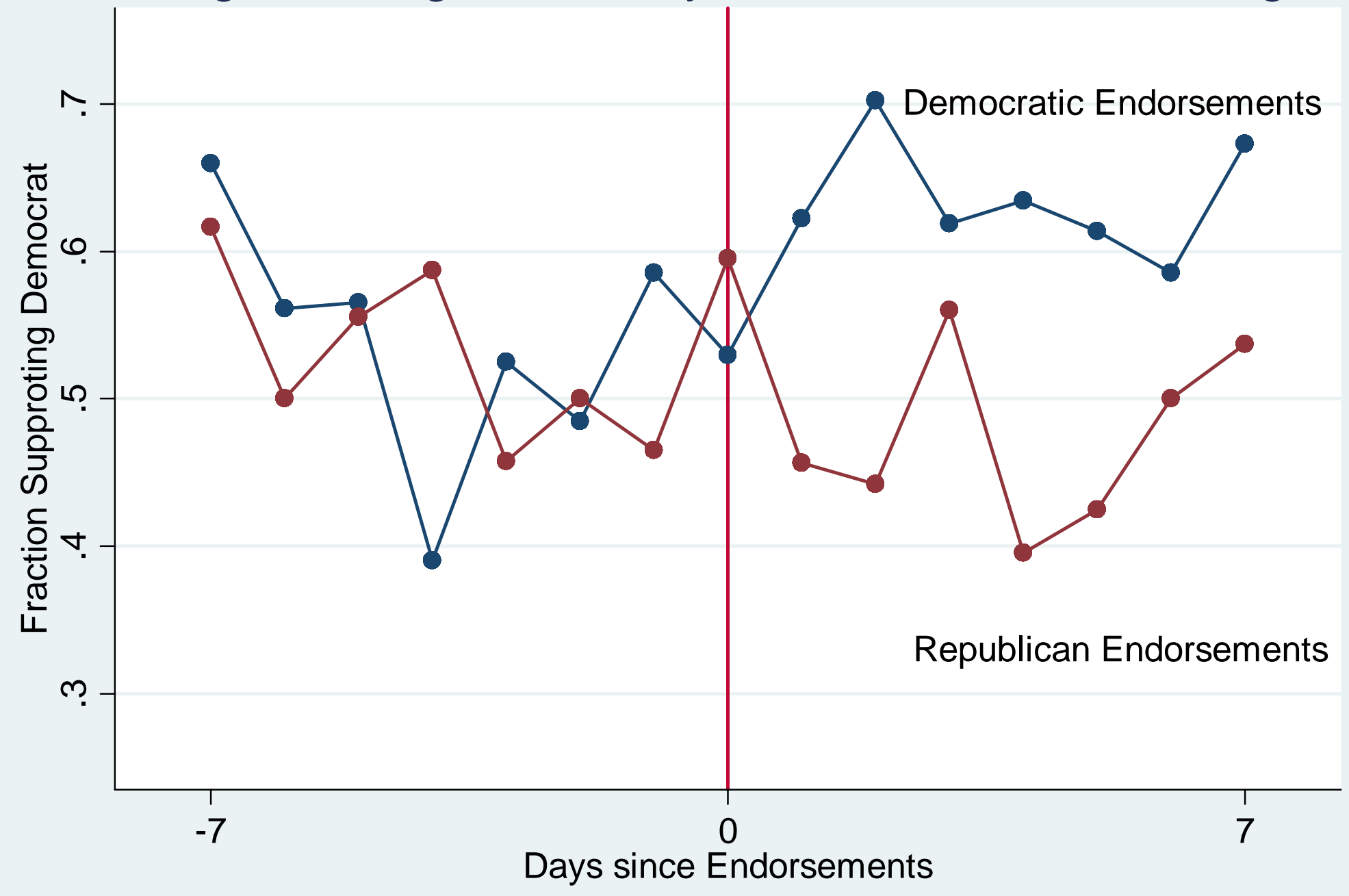


Figure 4: Low-Credibility Endorsements and Voting

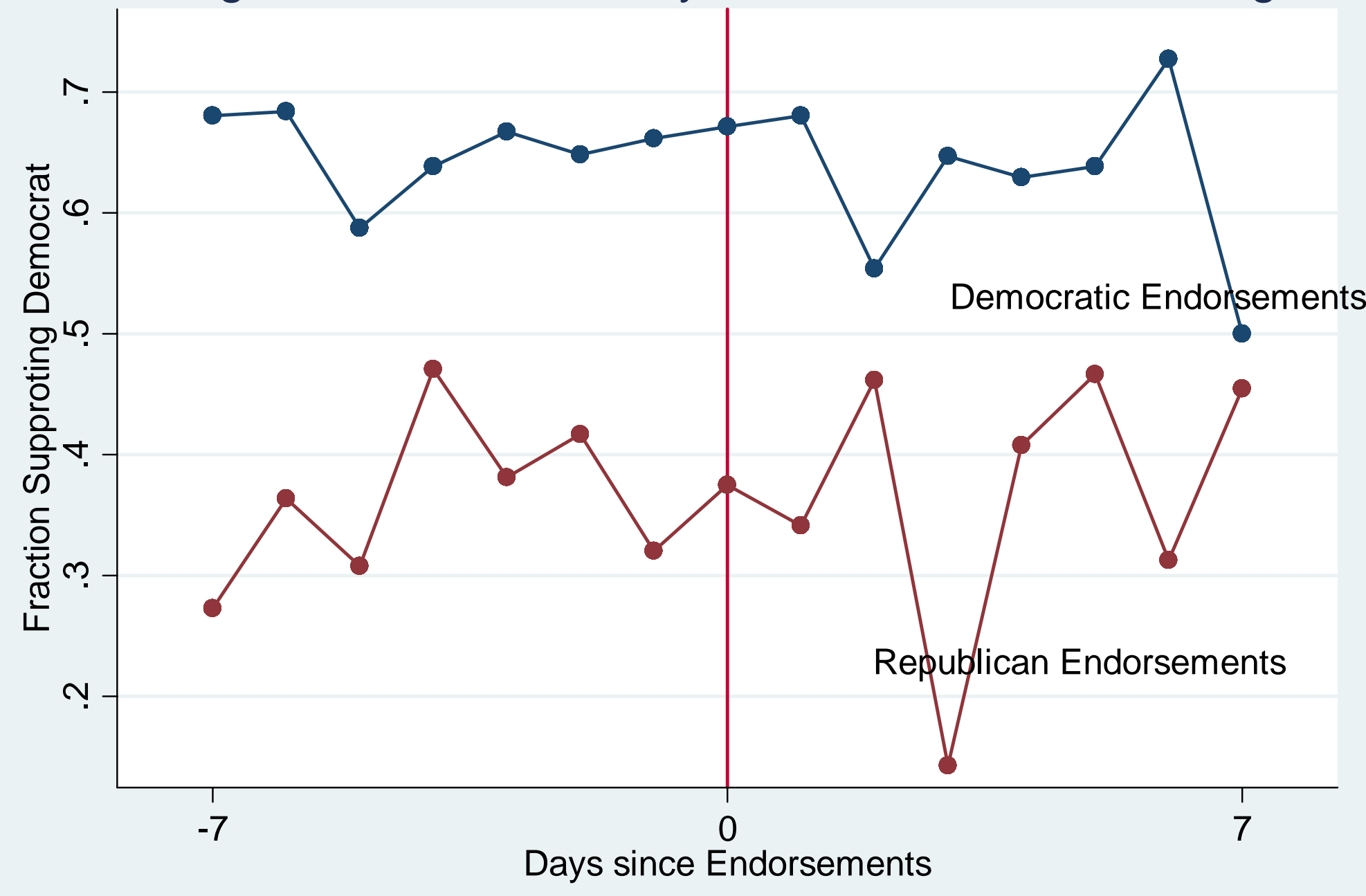


Table 1 Summary Statistics

\begin{tabular}{lrrrrr}
\hline \hline \multicolumn{1}{c}{ Variable } & Obs & Mean & Std.Dev. & Min & Max \\
\hline Intend to vote for Democratic Candidate & 32,014 & 0.544 & 0.498 & 0 & 1 \\
Have a high school degree, no college & 32,014 & 0.217 & 0.412 & 0 & 1 \\
Have some college or higher & 32,014 & 0.741 & 0.438 & 0 & 1 \\
Male & 32,014 & 0.473 & 0.499 & 0 & 1 \\
Black & 32,014 & 0.093 & 0.291 & 0 & 1 \\
Age & 32,014 & 47.225 & 15.973 & 18 & 97 \\
Born-again Christian & 32,014 & 0.312 & 0.463 & 0 & 1 \\
Attend religious services & 32,014 & 0.388 & 0.487 & 0 & 1 \\
Read newspaper with democratic endorsement & 32,014 & 0.593 & 0.491 & 0 & 1 \\
\hline \hline
\end{tabular}


Table 2A: First Stage -- Newspaper Ideology

\begin{tabular}{ll}
\hline \hline \multicolumn{2}{c}{ Dependent Variable: Endorse Democratic Candidate } \\
\hline Readers Preference & $4.073^{* * *}$ \\
& $(0.673)$ \\
Group owner effect ${ }^{a}$ & 0.269 \\
Advance Publications Inc. & $(0.280)$ \\
& $1.096^{* *}$ \\
Cox Newspapers & $(0.422)$ \\
& -0.164 \\
E W Scripps Co. & $(0.526)$ \\
& $0.910^{* * *}$ \\
Gannett Co. Inc & $(0.238)$ \\
& 0.463 \\
Hearst Newspapers & $(0.334)$ \\
& $1.043^{* * *}$ \\
Knight Ridder & $(0.324)$ \\
& -0.135 \\
Lee Enterprises Inc. & $(0.470)$ \\
& $1.634^{* * *}$ \\
McClatchy Newspapers & $(0.381)$ \\
& $0.870^{* *}$ \\
New York Times Co. & $(0.395)$ \\
& $0.322^{* *}$ \\
Year 2004 & $(0.155)$ \\
& $-2.500^{* * *}$ \\
Constant & $(0.377)$ \\
&
\end{tabular}


Table 2B: Second Stage: Effect of Newspaper Endorsements on Vote Intention

\begin{tabular}{|c|c|c|c|}
\hline \multicolumn{4}{|c|}{ Dependent Variable: 1 if intend to vote for the Democrat } \\
\hline & I & II & III \\
\hline \multirow[t]{2}{*}{ Credibility } & $0.029 * *$ & & $0.055 * *$ \\
\hline & $(0.013)$ & & $(0.026)$ \\
\hline \multirow[t]{2}{*}{ Endorsement } & & 0.011 & -0.020 \\
\hline & & $(0.008)$ & $(0.017)$ \\
\hline \multirow[t]{2}{*}{ High school } & $-0.047 * * *$ & $-0.047 * * *$ & $-0.047 * * *$ \\
\hline & $(0.016)$ & $(0.015)$ & $(0.016)$ \\
\hline \multirow[t]{2}{*}{ College } & -0.013 & -0.013 & -0.013 \\
\hline & $(0.016)$ & $(0.016)$ & $(0.016)$ \\
\hline \multirow[t]{2}{*}{ Male } & $-0.088 * * *$ & $-0.087 * * *$ & $-0.088 * * *$ \\
\hline & $(0.006)$ & $(0.006)$ & $(0.006)$ \\
\hline \multirow[t]{2}{*}{ Black } & $0.440 * * *$ & $0.440 * * *$ & $0.440 * * *$ \\
\hline & $(0.009)$ & $(0.008)$ & $(0.009)$ \\
\hline \multirow[t]{2}{*}{ Age } & $0.002 * *$ & $0.002 * *$ & $0.002 * *$ \\
\hline & $(0.001)$ & $(0.001)$ & $(0.001)$ \\
\hline \multirow[t]{2}{*}{ Age squared } & 0.000 & 0.000 & 0.000 \\
\hline & $(0.000)$ & $(0.000)$ & $(0.000)$ \\
\hline \multirow[t]{2}{*}{ Born again Christian } & $-0.150 * * *$ & $-0.150 * * *$ & $-0.150 * * *$ \\
\hline & $(0.007)$ & $(0.007)$ & $(0.007)$ \\
\hline \multirow[t]{2}{*}{ Attend religious activities } & $-0.123 * * *$ & $-0.123^{* * *}$ & $-0.123 * * *$ \\
\hline & $(0.006)$ & $(0.006)$ & $(0.006)$ \\
\hline \multirow[t]{2}{*}{ Constant } & $0.740 * * *$ & $0.740 * * *$ & $0.741 * * *$ \\
\hline & $(0.183)$ & $(0.189)$ & $(0.183)$ \\
\hline Income categories & Yes & Yes & Yes \\
\hline Newspaper fixed effects & Yes & Yes & Yes \\
\hline Date fixed effects & Yes & Yes & Yes \\
\hline Observations & 32014 & 32014 & 32014 \\
\hline
\end{tabular}

Standard errors in parentheses; * denotes 90\% significance; ** denotes 95\% significance; $* * *$ denotes $99 \%$ significance. 
Table 3: Influence of Top 20 Newspapers in $2000^{\mathrm{a}}$

\begin{tabular}{|c|c|c|c|c|c|}
\hline Newspaper & $\begin{array}{l}\text { Reader } \\
\text { support } \\
\text { for Gore }\end{array}$ & Group owner $^{\mathrm{b}}$ & $\begin{array}{c}\text { Probability } \\
\text { of endorsing } \\
\text { Gore }\end{array}$ & $\begin{array}{c}\text { Actual } \\
\text { endorsement }\end{array}$ & $\begin{array}{c}\text { Implied } \\
\text { influence }\end{array}$ \\
\hline New York Times & $75 \%$ & New York Times & $90 \%$ & Gore & $0.50 \%$ \\
\hline Washington Post & $64 \%$ & -- & $54 \%$ & Gore & $2.10 \%$ \\
\hline New York Daily News & $67 \%$ & -- & $58 \%$ & Gore & $1.90 \%$ \\
\hline Chicago Tribune & $53 \%$ & -- & $36 \%$ & Bush & $-1.70 \%$ \\
\hline Newsday & $57 \%$ & -- & $44 \%$ & Gore & $2.60 \%$ \\
\hline Houston Chronicle & $39 \%$ & Hearst & $34 \%$ & Bush & $-1.60 \%$ \\
\hline Dallas Morning News & $35 \%$ & -- & $17 \%$ & Bush & $0.90 \%$ \\
\hline Chicago Sun Times & $67 \%$ & -- & $58 \%$ & Bush & $-2.70 \%$ \\
\hline Boston Globe & $72 \%$ & New York Times & $89 \%$ & Gore & $0.50 \%$ \\
\hline San Francisco Chronicle & $74 \%$ & Hearst & $82 \%$ & Gore & $0.90 \%$ \\
\hline Arizona Republic & $41 \%$ & -- & $20 \%$ & Bush & $-1.00 \%$ \\
\hline New York Post & $49 \%$ & -- & $31 \%$ & Bush & $-1.50 \%$ \\
\hline Rocky Mountain News & $47 \%$ & -- & $28 \%$ & Bush & $-1.30 \%$ \\
\hline Denver Post & $52 \%$ & -- & $35 \%$ & Gore & $3.10 \%$ \\
\hline Philadelphia Inquirer & $59 \%$ & Knight Ridder & $82 \%$ & Gore & $0.90 \%$ \\
\hline Union-Tribune & $51 \%$ & -- & $34 \%$ & Bush & $-1.60 \%$ \\
\hline
\end{tabular}

${ }^{a}$ USA Today, Wall Street Journal and LA Times are not in this table because those newspapers did not make an endorsement or made a non-endorsement in 2000.

${ }^{\mathrm{b}}$ Missing (--) means that the newspaper is not owned by a group owner. Group owner is defined as a company that owns more than ten daily newspapers in the survey. 


\section{Table 4: Counterfactual Endorsement Scenarios}

\begin{tabular}{lcc}
\hline \hline & Year 2000 & Year 2004 \\
\hline $\begin{array}{l}\text { Vote share of the Democratic candidate in sample } \\
\text { Predicted change in Democratic vote share among }\end{array}$ & $53.25 \%$ & $55.41 \%$ \\
$\begin{array}{l}\text { readers if all newspapers made Democratic } \\
\text { endorsements }\end{array}$ & $+2.20 \%$ & $+1.74 \%$ \\
$\begin{array}{l}\text { Predicted change in Democratic vote share among } \\
\text { readers if all newspapers made Republican } \\
\text { endorsements }\end{array}$ & $-2.62 \%$ & $-3.12 \%$ \\
$\begin{array}{l}\text { Net effect among readers } \\
\text { Predicted change in Democratic vote share among }\end{array}$ & $+4.82 \%$ & $+4.86 \%$ \\
$\begin{array}{l}\text { voters if all newspapers made Democratic } \\
\text { endorsements }\end{array}$ & $+1.64 \%$ & $+1.30 \%$ \\
$\begin{array}{l}\text { Predicted change in Democratic vote share among } \\
\text { voters if all newspapers made Republican } \\
\text { endorsements }\end{array}$ & $-1.96 \%$ & $-2.34 \%$ \\
\begin{tabular}{l} 
Net effect among voters \\
\hline \hline
\end{tabular} & $+3.60 \%$ & $+3.64 \%$ \\
\hline
\end{tabular}




\section{Table 5: Alternative Explanations}

Dependent Variable: 1 if intend to vote for the Democrat

\begin{tabular}{lllll} 
& \multicolumn{1}{c}{$(1)$} & $(2)$ & $(3)$ & $(4)$ \\
After*Credibility & $0.023^{*}$ & $0.024^{* *}$ & $0.028^{* *}$ & $0.051^{* *}$ \\
& $(0.014)$ & $(0.011)$ & $(0.013)$ & $(0.022)$ \\
$\begin{array}{l}\text { Newspaper-specific trends } \\
\text { Ideology-specific trends }\end{array}$ & Yes & & & \\
Voter sample & & Yes & & \\
$\begin{array}{l}\text { Paper fixed effects } \\
\text { Date fixed effects }\end{array}$ & all & all & exclude & only \\
Observations & Yes & Yes & Yes & moderates \\
\hline Other control variables are included. Standard errors in parentheses; & Yes denotes $90 \%$ significance; \\
** denotes 95\% significance; *** denotes 99\% significance. & & Yes & Yes
\end{tabular}


Table 6: Timing of Endorsements

\begin{tabular}{c||cccc} 
& $10 / 17 / 2004$ & $10 / 24 / 2004$ & $10 / 31 / 20004$ & Total \\
\hline $10 / 22 / 2000$ & $13.04 \%$ & $10.14 \%$ & $1.45 \%$ & $24.63 \%$ \\
$10 / 29 / 2000$ & $30.43 \%$ & $30.43 \%$ & $7.25 \%$ & $68.11 \%$ \\
$11 / 5 / 2000$ & $1.45 \%$ & $4.35 \%$ & $1.45 \%$ & $7.25 \%$ \\
Total & $44.92 \%$ & $44.92 \%$ & $10.15 \%$ & $100 \%$
\end{tabular}

Notes: Based upon a sample of 69 newspapers that made endorsements on the three Sundays prior to the election in both 2000 and 2004. 11/5/2000 is the Sunday before the 2000 election, and 10/31/2004 is the Sunday before the 2004 election. 


\section{Table 7: Alternative Credibility Measures}

Dependent Variable: 1 if intend to vote for the Democrat

After*Surprise measure $\quad 0.047 * *$

After*Historical measure

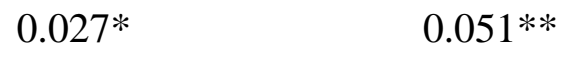

$(0.017)$

Sample all

Papers with sufficient $\quad$ Papers with more than 5

\begin{tabular}{llll} 
& & endorsement history $^{{ }^{a}}$ & historical endorsements \\
Paper fixed effects & Yes & Yes & Yes \\
Date fixed effects & Yes & Yes & Yes \\
Observations & 32014 & 14574 & 6457 \\
\hline \hline
\end{tabular}

${ }^{a}$ Historical credibility measure is derived from the probability of endorsing the democrat/republican candidates, which is calculated as the fraction of democratic/republican endorsements from historical record. The credibility measure is not well-defined when this fraction is either 1 or 0 , and newspapers that always supported the same political party are excluded from this specification.

Other control variables are included. Standard errors in parentheses; * denotes $90 \%$ significance; ** denotes $95 \%$ significance; *** denotes $99 \%$ significance. 
Table 8: Additional robustness checks

\begin{tabular}{lllll}
\hline \multicolumn{4}{c}{ Dependent Variable: 1 if intend to vote for the Democrat } \\
& I & \multicolumn{1}{c}{ II } & III & IV \\
After*Credibility & & & 0.020 & $0.036^{*}$ \\
& & & $(0.012)$ & $(0.021)$ \\
After*Credibility-Dem & 0.026 & & & \\
& $(0.024)$ & & & \\
After*Credibility-Rep & -0.033 & & & \\
& $(0.023)$ & & & \\
After*Credibility-2000 & & 0.015 & & \\
& & $(0.017)$ & & \\
After*Credibility-2004 & & 0.047 & & reader \\
& & $(0.019)^{* *}$ & & only 7-day \\
First-stage preference & reader & reader & market & readers \\
Voter sample & all & all & all & Yes \\
Paper fixed effects & Yes & Yes & Yes & Yes \\
Date fixed effects & Yes & Yes & Yes \\
Observations & 32014 & 32014 & 32014 & 15573 \\
\hline \hline
\end{tabular}

Other control variables are included. Standard errors in parentheses; * denotes $90 \%$ significance; ** denotes $95 \%$ significance; $* * *$ denotes $99 \%$ significance. 